\title{
Changes in the Characteristics of Water-in-Oil-based High Internal Phase Emulsion Containing Moringa Leaves Extract at Various Storage Conditions
}

\author{
Atif Ali $^{1,2 \star}$ and Naveed Akhtar ${ }^{2}$ \\ ${ }^{1}$ Institute of Pharmaceutical Sciences, University of Veterinary and Animal Sciences, Lahore- Pakistan; ${ }^{2}$ Department of \\ Pharmacy, Faculty of Pharmacy and Alternative Medicine, the Islamia University of Bahawalpur 63100, Bahawalpur- Pakistan
}

*For correspondence: Email: ajmaline2000@gmail.com; Tel: +92 334 6081922; Fax: +92 629255243

Received: 6 April 2013

Revised accepted: 1 April 2014

\begin{abstract}
Purpose: To explore changes in the characteristics of water-in-oil-based high internal phase emulsion containing Moringa oleifera (Moringa HIPE) extract at various storage conditions and time intervals.

Methods: Moringa leaves extract (3\%) was entrapped into HIPE. Color, liquefaction, conductivity, $\mathrm{pH}$, and centrifugation were assessed by keeping the samples of Moringa HIPE at 8, 25, 40 and $40{ }^{\circ} \mathrm{C}$, and $75 \% \mathrm{RH}$ (relative humidity) over time up to 54 days. Rheological measurements were made on freshly prepared emulsion and after one and two months. Data were analysed using Brookfield Software Rheocalc version (2.6) with IPC Paste and Power Law (PL) math models.

Results: There was no change in color, electrical conductivity, liquefaction and phase separation (after centrifugation) in any sample of Moringa HIPE at the various storage conditions and periods. The $\mathrm{pH}$ of freshly prepared Moringa HIPE was 5.5 which gradually decreased with slight variation in the storage conditions. The viscosity of freshly prepared emulsion was $3256.65 \mathrm{cP}$ and this decreased with increase in shear stress. Flow index and shear sensitivity factor of freshly prepared emulsion were 0.36 and 0.65 , respectively. The rheograms of Moringa HIPEs indicate non-Newtonian behaviour and pseudo-plastic tendency. Power Law and IPC paste provided the data of confidences of fit.

Conclusion: Moringa HIPE showed stability and can be guided exclusively to protect skin against ultraviolet radiation-mediated oxidative damage.
\end{abstract}

Keywords: Moringa oleifera, High Internal Phase Emulsion, Rheogram, Pseudoplastic, Non-Newtonian, Shear

Tropical Journal of Pharmaceutical Research is indexed by Science Citation Index (SciSearch), Scopus, International Pharmaceutical Abstract, Chemical Abstracts, Embase, Index Copernicus, EBSCO, African Index Medicus, JournalSeek, Journal Citation Reports/Science Edition, Directory of Open Access Journals (DOAJ), African Journal Online, Bioline International, Open-J-Gate and Pharmacy Abstracts

\section{INTRODUCTION}

High internal phase emulsions (HIPEs) are concentrated systems retaining a large volume of internal phase. Recently, both oil-in-water $(\mathrm{O} / \mathrm{W})$ and water-in-oil (W/O) systems with internal phase volume ratios of 99 have been investigated. They have a number of practical applications, some of which are gels and creams in cosmetic products, oil recovery from oil sands, petroleum gels as safety fuels and agricultural sprays with pesticidal properties. Understanding of the factors that govern the formation and stability of HIPEs is much undeveloped at present $[1,2]$.

The stability of emulsions depends on their physicochemical characteristics, such as droplet size, rheological characteristics, conductibility; inter-lamellar and free water distribution, behavior under centrifugation and different temperatures, among others [3]. 
Moringa oleifera (Moringaceae) is a pan-tropical species [4]. Bioactive compounds such as carotene, vitamins $\mathrm{C}, \mathrm{B}$ and $\mathrm{A}$, phenolics, carotenoids, etc, have been reported. Moringa oleifera leaves extract has antioxidant activity against hydroxyl, superoxide and peroxyl radicals' and thus, may play a role in the treatment of diseases involving free radicals and oxidative damage such as cancer and aging [5]. Incorporation of antioxidants and phenolic compounds topically has recently proved to be a promising strategy for protecting the skin against oxidative damage [6], but to the best of our knowledge, there are no previous studies on HIPE formulations of Moringa leaf extract and their influence on formulation stability.

This study investigated the changes in the characterisitics of water-in-oil high internal phase emulsion containing Moringa leaves extract at different storage conditions and time intervals.

\section{EXPERIMENTAL}

\section{Plant identification}

Air dried leaves of Moringa oleifera were gathered in July, 2010 from Dera Ghazi Khan, Pakistan. The leaves were identified by a taxonomist, Dr. Muhammad Arshad, at the Cholistan Institute of Desert Studies (CIDS), the Islamia University of Bahawalpur, Pakistan. The specimen (voucher no. MO-LE-09-10-31) was placed in the Herbarium of the Islamia University Bahawalpur.

\section{Materials}

Polysiloxane polyalkyl polyether copolymer (ABIL EM 90) was procured from Franken. Paraffin oil from Merck, Germany, Methanol and Phosphoric acid from BDH, England. Deionized water was obtained from the Pharmaceutical Labs of Department of Pharmacy, The Islamia University of Bahawalpur, Pakistan.

\section{Preparation of the extract}

The air-dried ground ( Mesh No. 80) plant material $(40 \mathrm{~g})$ was extracted with each of the solvent - aqueous methanol (methanol: water, $80: 20 \mathrm{v} / \mathrm{v}, 1 \mathrm{~L}$ ) - for $6 \mathrm{~h}$ at room temperature in a mechanical mixer (Euro-Star, IKA D 230, Germany). The extract was separated from the residue by filtering through Whatman no. 1 filter paper and further extracted twice with fresh solvent, and the extracts combined. The combined extracts were concentrated under reduced pressure at $45{ }^{\circ} \mathrm{C}$, using a rotary evaporator (Eyela, Co. Ltd. Japan). The concentrated extract was stored in a refrigerator $\left(-4^{\circ} \mathrm{C}\right)$, until used for analyses.

\section{Preparation of the Moringa HIPE}

Moringa HIPE was prepared using paraffin oil (14 $\%)$, ABIL EM 90 (emulsifier) (2\%), the extract (3 $\%)$, phosphoric acid $(0.2 \%)$, fragrance $(1 \%)$ and $(80.8 \%)$ deionized water. Both the oily and aqueous phases were heated to $70{ }^{\circ} \mathrm{C} \pm 5$ and mixed using a homogenizer (Euro-Star, IKA D 230, Germany) followed by the addition of phosphoric acid, extract and fragrance. The speed of the homogenizer was kept at $5000 \mathrm{rpm}$ for $15 \mathrm{~min}, 1000 \mathrm{rpm}$ for $5 \mathrm{~min}$ and then at 500 rpm till it was cool.

\section{Evaluation of free radical scavenging activity}

The free radicals scavenging activity of The $\mathrm{H}$ donor ability was assessed using methanol solution of DPPH, a stable nitrogen-centered free radical. DPPH shows maximum absorbency at $517 \mathrm{~nm}$, which decreases in the presence of $\mathrm{H}$ donor molecules. The DPPH stable free radical was used for the determination of free radical scavenging activity of test samples [7]. To $5 \mu$ of test sample, was added DPPH to make the volume up to $100 \mu \mathrm{l}$ in 96 well plates. The contents were mixed and incubated at $37^{\circ} \mathrm{C}$ for $30 \mathrm{~min}$ and the optical density measured at 517 $\mathrm{nm}$. Ascorbic acid was used as a reference/standard. Scavenging activity was determined as in Eq 1. The results were taken as mean \pm standard error of mean (SEM, $n=3$ ).

$\%$ DPPH scavenging activity $=\{(100-(\mathrm{ODt} / \mathrm{OD})\} \ldots . .(1)$

\section{Assessment of physical stability}

Physical stability was assessed by keeping the four samples of emulsions various storage conditions ranging from 8 to $40{ }^{\circ} \mathrm{C}$ at $75 \% \mathrm{RH}$ (relative humidity) and over a period of up to 60 days. Physical characteristics of Moringa HIPE, viz, color, conductivity, liquefaction, centrifugation and $\mathrm{pH}$ were evaluated under these conditions. Electrical conductivity was determined using a conductivity meter (WTW COND-197i, Germany); centrifugation using Centrifuge Machine (Hettich EBA 20, Germany); and $\mathrm{pH}$ with a $\mathrm{pH}$ meter (WTW $\mathrm{pH}$-197i, Germany). The centrifugal test was implemented at $25^{\circ} \mathrm{C} / 5000 \mathrm{rpm}$ for $10 \mathrm{~min}$ by placing a few grams of sample in a disposable stoppered centrifugal tube. Samples were gathered for the assessment of rheological performance and viscosity measurements at the initial time and after one and two months. 
Viscosity and rheological behavior were determined using a rotational rheometer with a cone-plate configuration (Brookfield DV-III Ultra) with a CP41 spindle. A Brookfield software program, Rheocalc V2.6 was also used for this purpose. Approximately $0.2 \mathrm{~g}$ sample was exercised for the tests at $25{ }^{\circ} \mathrm{C}$ and the test repeated three times, at 10 diffrent shear rates. Following the determination of flow type, flow curves were fitted to mathematical models (power law and IPC paste). Increased shear stresses were applied on the samples, and shear rates and changes in viscosity observed.

\section{Data analysis}

Data were analyzed by using Brookfield Software Rheocalc, version 2.6. IPC Paste and Power Law (PL) math models provide a numerically and graphically analyze the behavior of data sets.

\section{Power Law}

The Power Law equation is as shown in Eq 2.

$\mathbf{T}=k D^{n}$

where $\mathrm{T}=$ Shear Stress, $D=$ Yield Stress (stress at zero shear rate), $k=$ Plastic Viscosity, and $n=$ Shear Rate

The calculated parameters for this model are Flow Index (no units), Consistency Index (cP) and Confidence of Fit (\%)

\section{IPC Paste analysis}

This method is intended to calculate the Shear Sensitivity Factor and the 10 RPM viscosity value of Moringa HIPE. The Paste equation is shown in Eq 3

$\eta=k R^{n}$

where $\eta=$ Viscosity $(\mathrm{cP}), k=$ Consistency Multiplier, $R=$ Rotational Speed (RPM), $n=$ Shear Sensitivity Factor, The calculated parameters for this model are Shear Sensitivity Factor (no units), 10 RPM Viscosity (cP), and Confidence of Fit (\%)

\section{Statistical analysis}

SPSS 17.0 was used for data analysis using the two-way ANOVA for variation at different time intervals. The level of significance was $p<0.05$.

\section{RESULTS}

The antioxidant activity of plant extract and freshly prepared Moringa HIPE was 91 and 85 $\%$, respectively. The color of freshly prepared Moringa HIPE was half white and did not change after storage at temperature of up to $40{ }^{\circ} \mathrm{C}$ and $75 \% \mathrm{RH}$ for a period of up to 54 days. No significant changes in liquefaction, electrical conductivity and phase separation were observed under similar storage conditions.

The $\mathrm{pH}$ values of Moringa HIPE kept at various storage conditions and period are shown in Table 1. Viscosities and rheological results are given in Tables 2 and 3 while rheograms of Moringa HIPEs are shown in Fig 1 - 3

\section{DISCUSSION}

DPPH assay is extensively used to determine free radical scavenging capacity. The antioxidant potential of the extract is correlated to flavonoids, tannins, proteins and reducing sugars [8]. The formulation components present in the reaction mixture resulted in the lowering of anti-oxidant activity of Moringa HIPE [9].

There was no change in color in any sample of Moringa HIPE when kept at different storage conditions over the period of study. From the previous studies of Banso showed that phenolic contents may protect the formulation component

Table 1: $\mathrm{pH}$ values of Moringa HIPE kept under various storage conditions $(n=3)$

\begin{tabular}{|c|c|c|c|c|}
\hline \multirow[t]{2}{*}{ Time } & \multicolumn{4}{|c|}{ Storage temperature $\left({ }^{\circ} \mathrm{C}\right)$} \\
\hline & 8 & 25 & $40^{\circ} \mathrm{C}$ & $40^{\circ} \mathrm{C}+75 \% \mathrm{RH}$ \\
\hline $\mathbf{O h}$ & 5.5 & 5.5 & 5.5 & 5.5 \\
\hline $12 \mathrm{~h}$ & 5.5 & 5.5 & 5.2 & 5.2 \\
\hline $24 \mathrm{~h}$ & 5.4 & 5.4 & 5.12 & 5 \\
\hline $36 \mathrm{~h}$ & 5.32 & 5.32 & 4.9 & 5 \\
\hline $48 \mathrm{~h}$ & 5.24 & 5.24 & 4.7 & 4.9 \\
\hline $72 \mathrm{~h}$ & 5.2 & 5.2 & 4.6 & 4.7 \\
\hline 7 days & 5.17 & 5.1 & 4.5 & 4.6 \\
\hline 14 days & 5.1 & 5 & 4.4 & 4.55 \\
\hline 21 days & 5 & 5.3 & 4.35 & 4.6 \\
\hline 28 days & 5 & 5.2 & 4.3 & 4.6 \\
\hline 6 weeks & 4.95 & 5.15 & 4.31 & 4.55 \\
\hline 8 weeks & 4.9 & 5.1 & 4.22 & 4.5 \\
\hline
\end{tabular}


Table 2: Viscosity $(\mathrm{cP})$ of Moringa HIPEs under various storage conditions $(\mathrm{n}=3)$

\begin{tabular}{|c|c|c|c|c|c|c|c|c|c|}
\hline \multirow{3}{*}{ S/No. } & \multicolumn{9}{|c|}{ Sample viscosity } \\
\hline & \multirow{2}{*}{$\begin{array}{l}\text { Freshly } \\
\text { prepared }\end{array}$} & \multicolumn{2}{|c|}{$8^{\circ} \mathrm{C}$} & \multicolumn{2}{|c|}{$25^{\circ} \mathrm{C}$} & \multicolumn{2}{|c|}{ At $40^{\circ} \mathrm{C}$} & \multicolumn{2}{|c|}{ At $40^{\circ} \mathrm{C} / 75 \% R H$} \\
\hline & & $\begin{array}{c}4 \\
\text { weeks }\end{array}$ & $\begin{array}{c}8 \\
\text { weeks }\end{array}$ & $\begin{array}{c}4 \\
\text { weeks }\end{array}$ & $\begin{array}{c}8 \\
\text { weeks }\end{array}$ & $\begin{array}{c}4 \\
\text { weeks }\end{array}$ & $\begin{array}{c}8 \\
\text { weeks }\end{array}$ & 4 weeks & $\begin{array}{c}8 \\
\text { weeks }\end{array}$ \\
\hline 1 & 3256.65 & 4373.15 & 9108.22 & 6077.17 & 6363.69 & 2397.69 & 2699.29 & 4569.19 & 3453.28 \\
\hline 2 & 3194.02 & 4112.68 & 8650.34 & 5798.88 & 6141.60 & 2357.93 & 2645.82 & 4386.863 & 3331.2 \\
\hline 3 & 3104.38 & 3933.32 & 8243.64 & 5566.97 & 5956.53 & 2324.80 & 2601.27 & 4234.922 & 3229.59 \\
\hline 4 & 3015.96 & 3746.7 & 7864.71 & 5359.14 & 5799.93 & 2285.17 & 2563.57 & 4083.157 & 3131.96 \\
\hline 5 & 2930.1 & 3586.84 & 7561.46 & 5170.23 & 5644.16 & 2240.43 & 2531.25 & 3953.072 & 3037.51 \\
\hline 6 & 2845.27 & 3428.15 & 7258.43 & 4986.4 & 5509.16 & 2191.60 & 2493.2 & 3830.279 & 2955.6 \\
\hline 7 & 2770.36 & 3298.71 & 6983.85 & 4834.97 & 5372.19 & 2148.87 & 2459.89 & 3722.836 & 2874.59 \\
\hline 8 & 2696.68 & 3175.63 & 6732.70 & 4683.62 & 5251.33 & 2120.04 & 2430.51 & 3619.162 & 2803.07 \\
\hline 9 & 2621.78 & 3057.85 & 6501.08 & 4301.72 & 5143.90 & 2077.66 & 2404.39 & 3518.629 & 2739.50 \\
\hline 10 & 2548.1 & 2952.47 & 6277.97 & 4404.90 & 5039.84 & 2047.68 & 2373.09 & 3436.616 & 2682.62 \\
\hline
\end{tabular}

Table 3: Rheological parameters of Moringa HIPEs under various storage conditions $(n=3)$

\begin{tabular}{|c|c|c|c|c|c|c|c|c|c|c|}
\hline \multirow{2}{*}{ Model } & \multirow{2}{*}{$\begin{array}{c}\text { Rheological } \\
\text { parameter }\end{array}$} & \multirow{2}{*}{$\begin{array}{l}\text { Freshly } \\
\text { prepared }\end{array}$} & \multicolumn{4}{|c|}{ Week 4} & \multicolumn{4}{|c|}{ Week 8} \\
\hline & & & $8^{\circ} \mathrm{C}$ & $25^{\circ} \mathrm{C}$ & $40^{\circ} \mathrm{C}$ & $40^{\circ} \mathrm{C}+75 \% \mathrm{Rh}$ & $8^{\circ} \mathrm{C}$ & $25^{\circ} \mathrm{C}$ & $40^{\circ} \mathrm{C}$ & $40^{\circ} \mathrm{C}+75 \% \mathrm{RH}$ \\
\hline & $\begin{array}{l}\text { Consistency } \\
\text { index (cP) }\end{array}$ & 1493 & 896.9 & 765 & 75.3 & 395.3 & 1597 & 352.9 & 62.6 & 231 \\
\hline \multicolumn{10}{|c|}{ Power } & 0.60 \\
\hline & $\begin{array}{l}\text { Confidence } \\
\text { of fit (\%) }\end{array}$ & 99.6 & 99.7 & 99.4 & 99.5 & 99.8 & 99.8 & 99.9 & 99.9 & 99.8 \\
\hline \multirow{3}{*}{$\begin{array}{l}\text { IPC } \\
\text { Paste }\end{array}$} & $\begin{array}{l}\text { Viscosity } \\
\text { (cP) }\end{array}$ & 216.9 & 144.9 & 163.2 & 35.3 & 104.1 & 282.2 & 119.3 & 34.6 & 70.4 \\
\hline & $\begin{array}{l}\text { Shear } \\
\text { sensitivity }\end{array}$ & 0.64 & 0.61 & 0.52 & 0.25 & 0.45 & 0.58 & 0.36 & 0.20 & 0.40 \\
\hline & $\begin{array}{l}\text { Confidence } \\
\text { of fit (\%) }\end{array}$ & 99.6 & 99.7 & 99.4 & 99.5 & 99.8 & 99.8 & 99.9 & 99.9 & 99.8 \\
\hline
\end{tabular}

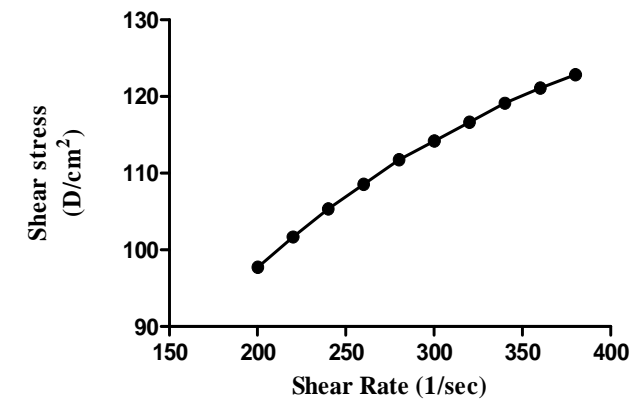

Figure 1: Rheograms of freshly prepared Moringa HIPE at $25^{\circ} \mathrm{C}$

from microbial growth of microorganisms which can release such substances which are able to change the color of the formulation [10].

There was no liquefaction in any of the samples under the storage conditions studied, thus indicating that Moringa HIPE was stable. After manufacturing of emulsions, temperature and time-dependent factorss can affect separation of

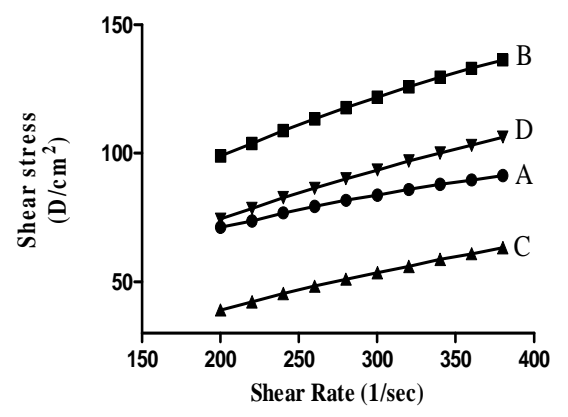

Figure 2: Rheograms of Moringa HIPEs Week 4 kept at (A) $8{ }^{\circ} \mathrm{C}$, (B) $25^{\circ} \mathrm{C},(\mathrm{C}) 40^{\circ} \mathrm{C}$ and (D) $40^{\circ} \mathrm{C}+75 \% \mathrm{RH}$

the phases leading to decrease in viscosity which results in increased liquefaction [11].

Conductivity is an assessment of extent presence of free ions [12]. No electrical conductivity was found in any sample Moringa HIPE throughout the study period. This is because the emulsion was of w/o type and oil being the continuous phase does not permit conduction of current. 


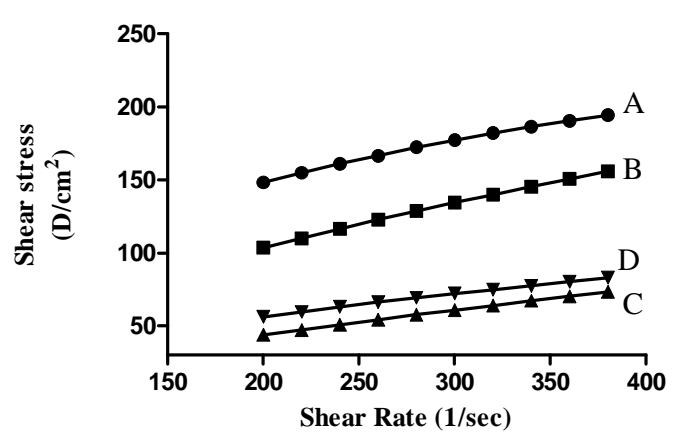

Figure 3: Rheograms of Moringa HIPEs Week 8 after storage at (A) $8^{\circ} \mathrm{C},(B) 25^{\circ} \mathrm{C},(\mathrm{C}) 40^{\circ} \mathrm{C}$ and (D) 40 ${ }^{\circ} \mathrm{C}+75 \% \mathrm{RH}$

Centrifugation is one of amongst physicochemical factors at which stability of cream is dependent [13]. Moringa HIPEs samples were largely stable all through the study period. After manufacture of emulsions, temperature and time-dependent factors may result in phase separation [11]. Elevated temperature can cause change in viscosity thus leading to phase separation.

The $\mathrm{pH}$ of freshly prepared Moringa HIPEs showed gradual decrease over time. It was also observed from the study of Naveed et al that decrease in $\mathrm{pH}$ may be due to presence of metabolites or decomposition of some other ingredients, such as paraffin oil, at accelerated conditions [11].

Rheological analyses are necessary to define and optimize stability and permit assessment of emulsions that undergo changes induced by aging, shear and temperature and stability [14]. Viscosity decreased in parallel with increase in shear stress.

The rheograms indicate non-Newtonian behavior, with flow index $<1$, indicating pseudoplastic tendency. Power Law was found to fit to all the rheograms and the confidence of fit was in the range of $99.4-99.9 \%$. IPC paste provides the data of confidence of fit of $99.5-99.9 \%$. It has also been observed that emulsions show a marked non-Newtonian behavior [15]. The results were in agreement with those of Saravacos and Kostoropolous who reported that most fruit and vegetable fluids, and pastes and emulsions are pseudoplastic, where flow behavior index varies from 0 to 1 [16]. It has also been reported that formulations with a pseudoplastic flow cause the production of a coherent film covering the skin surface. This characteristic is beneficial and crucial for better phenolic anti-oxidant protection of the skin surface. The reason for pseudo plastic flow may be due to the progressive disintegration of the internal structure of the emulsions, under increasing shear, and its later reconstruction by means of Brownian movement [17].

Although flow index was changed by stress, so also was the consistency index of Moringa HIPEs. Most researchers have reported that consistency index normally declines during storage due to product instability [18], but in our work, consistency index increased for the emulsions. It is possible that this was due to the interaction of phenolic compounds and ingredients of the emulsion. This interaction has been demonstrated by Guaratini when the decomposition products were analyzed by mass spectrometry [19].

Thus, emulsion system proposed in this study is acceptable and stable only if the product is to be used in a restricted period of time.

\section{CONCLUSIONS}

Rheological assessment is a valuable interactive and forecasting tool for determining product consistency and quality. Moringa HIPE had good consistency and rheological results. The rheograms of all formulations showed nonNewtonian behavior, which is a desired rheological property as it promotes pseudoplastic tendency. Due to the stability of Moringa HIPEs, the emulsion should be evaluated in vivo to ascertain its suitability and efficacy for the treatment of skin disorders.

\section{ACKNOWLEDGEMENT}

The authors wish to thank Higher Education Commission of Pakistan for providing financial support to conduct the study. The authors also acknowledge the moral support given by the Chairman and Dean of the Faculty of Pharmacy \& Alternative Medicine, the Islamia University of Bahawalpur, Pakistan.

\section{REFERENCES}

1. Kizling $J$, kronberg B, Erikssion JC. On the formation and stability of high internal phase O/W emulsions. Adv Colloid Interfac Sci. 2006; 123: 295-302.

2. Gallegos C, Franco JM. Rheology of food, cosmetics and pharmaceuticals. Curr Opin Colloid Interfac Sci. 1999; 4: 288-293.

3. Baby AR, Santoro DM, Velasco MVR, Dos Reis Serra $\mathrm{CH}$. Emulsified systems based on glyceryl monostearate and potassium cetyl phosphate: scale-up and characterization of physical properties. Int J Pharmaceut. 2008; 361: 99-103.

4. Iqbal S, Bhanger M. Effect of season and production location on antioxidant activity of Moringa oleifera leaves grown in Pakistan. J Food Compos Anal. 2006; 19: 544-551. 
5. Anwar F, Latif S, Ashraf M, Gilani AH. Moringa oleifera: A Food Plant with Multiple Medicinal Uses. Phytother Res. 2007; 25:17-25.

6. Svobodova A, Psotova J, Walterova D. Natura phenolics in the prevention of UV-induced skin damage. A review. Biomed Papers. 2003; 147: 137-145.

7. Hamid K, Rani M, Kaniz S, Urmi F, Habib R, Rahman $M M$. Screening of different parts of the plant pandanus odorus for its antioxidant activity. Inter $J$ App Biol Pharmaceut Technol. 2010; 1: 1364-1368.

8. Aneta Wojdyło, Jan Oszmiannski RC. Antioxidant activity and phenolic compounds in 32 selected herbs. Food Chem. 2007; 105: 940-949.

9. Padilla A, Palma M, Barroso GC. Determination of phenolics in cosmetic creams and similar emulsions. J Chormatogra A. 2005; 1095: 83-88.

10. Banso A. Phytochemical and antibacterial investigation of bark extracts of Acacia nilotica. J Med Plant Res. 2009; 3: 082-085.

11. Naveed A, Shaiq-uz-zaman, Barkat AK, Haji MSK, Mahmood A, Fatima R, Tariq M, Akhtar R. Evaluation of skin various functional skin parameters using a topical cream of calendula officinalis extract. Afr J Pharm Pharmaco. 2011; 5 : 199-206.

12. Rubalya $S$, valantina, neelamegham, Gayathri $S$. Antioxidant stability of edible oil using rheological behaviour and in vitro analysis. Asian $\mathrm{J}$ Chem. 2009; 21(6); 4325-4332.

13. Baby AR, Santoro DM, VelascoMVB, Serra CHDR. Emulsified systems based on glyceryl monostearate and potassium cetyl phosphate: scale-up and characterization of physical properties. Int J Pharmaceut. 2008; 361: 99-103.

14. Tadros TF. Application of rheology for assessment and prediction of the long-term physical stability of emulsions. Adv Colloid Interfac. 2004; 108(109): 227-258.

15. Pal R. Rheology of polymer thickened emulsion. $J$ Rheol. 1992; 36: 1245-1259.

16. Saravacos GD, Kostaropoulos AE. Transport properties in processing of fruits and vegetables. Food Technol. 1995; 49: 99-105.

17. Choi MH, Jeong S, Nam SI, Shim SE, Chang YH. Rheology of decamethylceclopentasiloxane (cyclomethicone) W/O Emulsion System. Macromol Res. 2009; 17(12): 943-949.

18. Gaspar LR, Maia CPMBG. Rheological behavior and the SPF of sunscreens. Int J Pharmaceut. 2003; 250: 35-44.

19. Guaratini T, Gianeti MD, Campos PMBGM. Stability of cosmetic formulations containing esters of vitamins $E$ and A: chemical and physical aspects. Int $J$ Pharmaceut. 2006; 327(1-2): 12-16. 